\title{
Editorial
}

\section{Folic acid follies}

Can dietary supplements prevent cancer? The Journal of the American Medical Association recently published results from the Polyp Prevention Study Group ${ }^{1}$. This randomised controlled trial investigated the safety and efficacy of folic acid supplementation for preventing colorectal adenomas in participants with a recent history of colorectal adenomas.

The average age of the participants was 57 years, and 64\% were men. All participants had a recent history of colorectal adenoma. The nine participating clinical centres were scattered all over the USA, plus one in Toronto. Participants were randomised into two groups, and provided either with $1 \mathrm{mg}$ of folic acid a day or placebo. The follow-up consisted of colonoscopic investigations after 3 years and $6-8$ years. The outcome measures were (1) colorectal adenomas and (2) advanced lesions categorised, for example, as highgrade dysplasia or invasive cancer. The results showed that the risk of colorectal adenoma at the second follow-up was higher in those participants who received folic acid than in the placebo group.

In an editorial in the same journal ${ }^{2}$, Ulrich and Potter comment that this trial shows once again that it is a bad idea to try to use just one agent to prevent cancer. This conclusion has already been drawn from the ATBC study ( $\alpha$-Tocopherol, $\beta$-Carotene Lung Cancer Prevention Study $)^{3}$ and CARET study ( $\beta$-Carotene and Retinol Efficacy Trial) ${ }^{4}$, which showed that the use of high-dose $\beta$-carotene supplements seems to increase the risk of lung cancer in smokers. Furthermore, this is not a primary prevention study. The patients who were selected for this trial already had a diagnosis of colorectal adenoma, so the results could in any case not to be taken as valid for the whole population.

\section{Food is not equal to pills}

Many medically trained researchers are still looking for the hidden treasure in the wrong place. Of course it would simplify life if we could tell people to just add a pill a day and this would certainly add to the profits of the pharmaceutical industry. But there are no magic bullets.

The urgent task now is to emphasise to consumers, and health professionals, that the solution to health problems is rarely to be found in food supplements. In this case, with patients at higher risk of colon cancer, the supplements seem to provide a clearly increased risk of disease progression. People with an increased risk of cancer are best advised to eat healthy diets, and not to pop pills.

The trial is important news. The results should be disseminated widely, especially to people at high risk of colorectal cancer. The results should be taught to our nutrition students, in parallel with the results from $\mathrm{ATBC}^{3}$ and CARET $^{4}$. Single-agent chemoprevention of cancer does not work ${ }^{2}$.

\section{Agneta Yngve}

Editor-in-Chief

\section{References}

1 Cole BF, Baron JA, Sandler RS, Haile RW, Ahnen DJ, Bresalier RS, et al. Folic acid for the prevention of colorectal adenomas: a randomized clinical trial. JAMA: Journal of the American Medical Association 2007; 297(21): 2351-9.

2 Ulrich CM, Potter JD. Folate and cancer - timing is everything. JAMA: Journal of the American Medical Association 2007; 297(21): 2408-9.

3 The $\alpha$-tocopherol, $\beta$-carotene lung cancer prevention study: design, methods, participant characteristics, and compliance. The ATBC Cancer Prevention Study Group. Annals of Epidemiology 1994; 4(1): 1-10.

4 Smigel K. $\beta$ Carotene fails to prevent cancer in two major studies; CARET intervention stopped. Journal of the National Cancer Institute 1996; 88(3-4): 145. 